\title{
A narrative study on the life of organ procurement coordinator
}

\author{
Ha Young Song ${ }^{1}$, Han Ik Cho ${ }^{2}$, Wonhyun $\mathrm{Cho}^{1}$, Chunhee Bok ${ }^{1}$ \\ ${ }^{1}$ Department of Yeongnam Management, Korea Organ Donation Agency, Seoul, Korea \\ ${ }^{2}$ Department of Education, Gyeongsang National University, Jinju, Korea
}

Background: Organ procurement coordinators (OPC) are the first person to approach the family when a potential brain death patient is referred and play a key role in attracting the donation of organs and the family's consent. Thus, it is necessary to listen to their real stories and to understand their experience.

Methods: This study used a narrative inquiry method developed by Clandinin and Connelly (2000) as a method to inquire the lives of OPC and to understand the meaning of such an experience. Three coordinators who have been worked at Korea Organ Donation Agency as a coordinator for more than 3 years and are working in Youngnam region. Data collection was done for 3 months from May 2019 to August 2019.

Results: The meaning of their relationship with organ families were that in their first encounter with donor family, they are trying their best to sympathize with their pain, to support them emotionally, and to relieve their pain. However, there was a conflict over what seemed to be trying to persuade organ donation by coordinator and a negative perception about organ donation. About relationship with the hospital include the confusion about working place where they have to move to a different hospital every day and the conflict with the hospital staff.

Conclusions: This study was conducted to understand the experience of OPC through narrative inquiry. We tried to understand the work of OPC by approaching the whole course of their life comprehensively, not as a part of task and to understand the vivid experience of the OPC. The result of this study can be used as a basic data for the direction and design of future studies.

Corresponding author: Ha Young Song

E-mail: sgloomy@naver.com

(C) The Korean Society for Transplantation

This is an Open Access article distributed under the terms of the Creative Commons Attribution Non-Commercial License (http://creativecommons.org/licenses/by-nc/4.0/) which permits unrestricted non-commercial use, distribution, and reproduction in any medium, provided the original work is properly cited. 